\title{
The Role of 18F-FDG-PET/CT Scan in the Management of Multiple Myeloma
}

\section{Shirin Haghighat}

Shiraz University of Medical Science, Hematology and Medical Oncology Department, Shiraz, Iran.

\begin{abstract}
Bone lesion is a myeloma-defining event which is reported in $80 \%$ of multiple myeloma patients. Imaging of bone is essential in the evaluation of pattern and extent of bone involvement. Recently, whole body X ray (WBXR) has been replaced by more accurate imaging such as whole body MRI and FDG-PET/CT scan. This review article provides the advantages and role of PET/CT scan in the diagnosis and management of multiple myeloma patients. Generally, PET/CT in diagnosis of bone involvement of newly diagnosed myeloma patients is more sensitive than WBXR. The prognostic value of PET/CT in newly diagnosed patients has been described as well. Different studies have demonstrated that several PET parameters such as the number of focal lesions (FL), SUVmax and extramedullary disease (EMD) may affect the outcome of multiple myeloma patients. Interstingely, the main role of PET/CT in myeloma patients is treatment response monitoring and to some extent assessment of MRD. $\mathrm{PET} / \mathrm{CT}$ appears to be superior than MRI in the evaluation of response due to its ability in differentiating active lesion from negative one.
\end{abstract}

Keywords: Multiple myeloma- PET- prognosis and treatment

Asian Pac J Cancer Care, 5 (2), 119-123

Submission Date: 04/29/2020Ａcceptance Date: 06/19/2020

\section{Introduction}

Infiltration and expansion of malignant monoclonal plasma cells, basically in the bone marrow causes multiple myeloma (MM) [1]. As indicated by the global cancer statistics $2018, \mathrm{MM}$ represented $0.9 \%$ of all new malignancies and $1.1 \%$ of leading causes of cancer death worldwide in 2018 [2]. According to the global burden of multiple myeloma study, age-standardized incidence and mortality were highest in the Australasian, North American, and Western European regions and lowest in Asia, Oceania, and sub-Saharan Africa [3]. It is a proven fact that multiple myeloma develops from an asymptomatic premalignant condition clinically identified as monoclonal gammopathy of undetermined significance (MGUS) [4-5]. Hypercalcemia, anemia, renal function impairment, and bone lesions are classic $\mathrm{CRAB}$ features which are currently established diagnostic criteria for symptomatic MM [6]. Recently, International Myeloma Working Group has revised the criteria of diagnosis of MM and has mentioned the use of computed tomography (CT) scan and positron emission tomography (PET) scanning in addition to skeletal radiography to diagnose lytic bone lesions [7]. The most accepted staging system in patients affected by MM includes the international staging system (ISS) and Durie-Salmon staging system (DSS) [8]. The ISS is an easy risk scoring system that includes two parameters; serum $\beta_{2}$-microglobulin level and serum albumin level. This risk stratification system which is established in 2005, classified MM patients into three prognostic groups with different overall survival [9]. DSS predicts survival on the base of four parameters; M component production rate, hemoglobulin concentration, calcium value and the number of lytic bone lesions on X-ray [10]. Interpretation of bone lesions on $\mathrm{X}$-rays have some limitation, so new Durie-salmon plus staging system was developed in 2006 which integrated new imaging techniques such as whole-body CT scan, magnetic resonance imaging (MRI) and whole-body FDG-PET scanning into anatomic and functional staging [11]. Bone involvement is one of the most frequent presentation of multiple myeloma, observed in about

Corresponding Author:

Dr. Shirin Haghighat

Shiraz University of Medical Science, Hematology and Medical Oncology, Shiraz, Iran.

Email: sh.haghighat2010@yahoo.com 
two-thirds of patients at the time of diagnosis and in approximately all patients in the course of their diseases [12]. Therefore imaging could be an essential part of the approach to multiple myeloma for detection of lytic bone lesions and identification of extramedullary disease to demonstrate the need for early treatment [12]. Although plain X-rays have been easily available skeletal surveys for a long time, it has a major limitation. Osteolytic bone lesions could be only detectable if at least $30 \%$ of trabecular bone is lost [13-14]. More sensitive imaging modalities such as CT, MRI, and PET can be used as an alternative to detect lytic bone lesions at the earlier stage of disease efficiently [15]. The European Society of Medical Oncology (ESMO) and European Myeloma Network (EMN) guidelines recommend a whole-body low dose CT scan as a new standard imaging for the detection of osteolytic bone lesions. These guidelines also recommend MRI and FDG-PET/CT scans to provide more details according to their availability [16-17]. In this article, I focus primarily on the role of FDG-PET/CT scan in the diagnosis, staging, therapy assessment and detection of minimal residual disease.

\section{Diagnostic value of FDG-PET CT scan}

$\mathrm{PET} / \mathrm{CT}$ scan by using FDG as a radiotracer can detect the glucose hypermetabolism of medullary and intramedullary lesions and gives properly both morphological and functional information [14-18]. It is widely accepted that whole-body PET/CT and MRI are equal in detecting focal bone lesions at diagnosis, however, MRI is more powerful at detecting diffuse disease and $\mathrm{PET} / \mathrm{CT}$ is more reliable in detecting extramedullary diseases [19-20-21)]. National Oncologic PET Registry (NOPR) has recently published the impact of PET/CT on intended management of 16 different cancer types which reported the highest frequency of a change in intended treatment in multiple myeloma $(48.7 \%)$ compared to other types of cancers [22]. A high impact of PET on the management of patients with plasma cell disorder has been also demonstrated in a Canadian retrospective study with a change in the planned approach in more than $2 / 3$ of patients [15]. A significant correlation between $18 \mathrm{~F}-\mathrm{FDG}$ parameters (SUVs and kinetics) and bone marrow plasma cell infiltration was approved in 40 patients with primary symptomatic multiple myeloma by a German study in 2015 [23]. Several studies have illustrated the sensitivity and specificity ranging from $75 \%$ to $100 \%$ in detecting lytic bone lesions and staging by PET/CT scan [24-25]. In patients with nonsecretory multiple myeloma who do not have any measurable parameters, more sensitive skeletal survey methods like PET/CT scan can assess the stage of the disease [26]. Another condition in which PET/ CT scan continues to be a considerable topic is solitary plasmacytoma, a single bone or soft tissue mass of clonal plasma cell with no or small bone marrow plasmacytosis. A panel of expert European hematologists recommended PET/CT or MRI, at least one of them, as a mandatory imaging modalitiy in a case of solitary plasmacytoma to exclude the presence of additional lesions [27]. The last IMWG guideline also recommends the PET/CT scan for the first evaluation of patients with solitary extramedullary plasmacytoma [1].

\section{The role of PET/CT in the assessment of prognosis}

Several studies have shown the prognostic value of $\mathrm{PET} / \mathrm{CT}$ in patients with smoldering multiple myeloma (SMM) and MM. A prospective study of a cohort of 120 patients with SMM has shown the probability of progression to $\mathrm{MM}$ in 2 years is $58 \%$ for patients with positive PET/CT versus 33\% for PET/CT-negative patients [28]. Siontis et al. also showed that patients with SMM who have positive PET/CT scans are at higher (75\%) risk of progression to symptomatic MM within 2 years [29]. These studies support the use of PET/CT scan to identifying the patients with SMM at higher risk of progression to symptomatic MM who are probably candidates for early initiation of treatment. Bartel et al. demonstrated the impact of PET/CT parameters such as the number of focal lesions (FL), presence of extramedullary disease (EMD), and SUV of lesions on the survival outcome of patients affected by MM [30]. Another Italian study has prospectively evaluated the prognostic significance of the same PET/CT parameters in patients with MM. This study revealed that $F L \geq 3, S U V>4.2$, and EMD in PET/CT associated with shorter PFS and OS [31].

Volume-based PET parameters such as metabolic tumor volume (MTV) and total lesion glycolysis (TLG) have been used to measure the metabolic activity of the tumor. Fonti et al. reviewed retrospectively medical data of 47 patients with newly diagnosed untreated MM and measured MTV, determined by FDG-PET/CT. They demonstrated the value of MTV in the prediction of PFS and OS in myeloma patients [32]. Similarly, another study by McDonald et al. found the useful survival implication of MTV and TLG. They also demonstrated the superiority of these volumetric measurements on the number and SUV of focal lesions in the prediction of OS and PFS [33]. A Chinese study has found the correlation between ki-67 expression and increase in FDG uptake in PET/CT in patients with EMM. They have also shown the prognostic implication of combination of ki-67 expression and SUVmax in PET in EMM patients [34]. In another study, Cengiz et al. reported that there was a significant correlation between bone marrow FDG uptake and percentage of CD38- and CD-138 expressing plasma cell. They also revealed the correlation between FDG uptake and some prognostically relevant laboratory parameters such as $\beta 2 \mathrm{M}$ and CRP [35]. As well the correlation between SUVmax in bone lesions and clinical parameters related to tumor burden such as high $\mathrm{M}$ protein, plasma cell $>20 \%$ in bone marrow, $\beta 2 \mathrm{M}>3.5 \mathrm{mg} / \mathrm{dl}$, hypercalcemia at the onset of disease, and increased LDH was reported by Li et al [36].

\section{Evaluation of treatment response with F-FDG PET/CT}

18 F-FDG PET/CT is a superior imaging modality to evaluate the response to treatment because it can distinguish between active and inactive lesions [12]. Several studies have demonstrated that post-treatment PET negativity correlates with a significant response to 
therapy. They have found the correlation between FDG suppression before transplantation and better outcome [30-31]. Caldarrela et al. have confirmed the usefulness of FDG PET/CT in assessing the response to treatment in a systematic review of 10 studies involving 690 patients with multiple myeloma and solitary plasmacytoma. They also found that response to treatment could be shown by FDG-PET earlier than other imaging tools such as MRI and whole-body X-ray [37]. Another retrospective study of 282 patients with MM showed that in patients achieving conventionally complete response (CR), positive PET associated with two times higher risk of progression compared to negative PET [38]. Several studies have compared FDG-PET with whole-body MRI in post-treatment setting to provide information about the persistent disease. They confirmed that MRI may have falsely positive results due to persistent signal abnormalities in non-active lesions. While the unique role of PET/CT in the evaluation of response to treatment has been proved [39-40]. Another study on 19 patients with multiple myeloma has demonstrated that FDG-PET before and after the first cycle of chemotherapy may be helpful to identify the patients who would respond to this chemotherapy [41]. In recent years, modern combination therapies in newly diagnosed MM patients have improved the depth of response and have increased the minimal residual disease negativity [42]. several meta-analysis and reviews have shown that MRD negativity associated with increased OS and PFS [43-44]. Therefore, improving the currently employed assays to detect the MRD may be considered one of the major goals in the management of MM patients. Different studies have evaluated the complementary role of PET/CT to existing methods such as bone marrow techniques, multiparameter flow cytometry (MFC) and next-generation sequencing (NGS). They reported higher OS in MRD-/PET- or MRD+/ PET- patients (4-year OS 94.2 and $100 \%$ respectively) compared to PET+ patients (4-year OS 73.8\%) [45].

\section{What are the limitations of the FDG-PET scan?}

Although the usefulness of PET/CT in diagnosis, staging and treatment monitoring has been suggested by several studies some reviews have demonstrated the limitations of PET/CT in this issue. Limited availability and higher cost compared to conventional imaging are the major causes of less application of PET/CT in the diagnosis and management of multiple myeloma in some institutes. False-positive results may be observed in different inflammatory conditions (such as thyroiditis, inflammatory bowel disease, and esophagitis), chemotherapy within the past 4 weeks, and radiotherapy within the past 2-3 months. Patients who received granulocyte colony-stimulating factors (GCSF) recently may show false positive uptake of FDG in the bone marrow [46]. Post-surgical and fracture areas can be other important causes of false-positive results in the FDG-PET scan [21]. False-negative results including hyperglycemia and recent use of high dose glucocorticoids are other limitations of FDG-PET for evaluation of patients with multiple myeloma. Sequestration phenomenon may be a potential pitfall in interpreting the post-therapy FDG-PET in myeloma patients. Heavily bone marrow infiltration by tumoral cells causes sequestration of $18 \mathrm{~F}-\mathrm{FDG}$ tracer in the bone marrow and lower availability of tracer to detect other sites of active disease. Successful treatment of bone marrow infiltration leads to an increase in the metabolic activity of residual disease then misinterpretation of the residual lesions as a progressive disease [47].

In conclusion, this mini-review shows that available evidence on the value of PET/CT in diagnosis, staging, prognosis and response monitoring is promising. PET/CT can detect myeloma bone lesions with a sensitivity higher than WBXR and comparable to MRI. It may also provide significant prognostic information in smoldering myeloma and solitary plasmacytoma. Interestingly, PET/CT could be a useful tool to monitor the treatment response due to its ability to detect the metabolic activity in lesions.

\section{Conflict of interest}

No potential conflict of interest relevant to this article was reported.

\section{References}

1. Hillengass J, Usmani S, Rajkumar SV, Durie BGM, Mateos M, Lonial S, Joao C, Anderson KC, García-Sanz R, Riva E, Du J, van de Donk N, Berdeja JG, Terpos E, Zamagni E, Kyle RA, San Miguel J, Goldschmidt H, Giralt S, Kumar S, Raje N, Ludwig H, Ocio E, Schots R, Einsele H, Schjesvold F, Chen W, Abildgaard N, Lipe BC, Dytfeld D, Wirk BM, Drake M, Cavo M, Lahuerta JJ, Lentzsch S. International myeloma working group consensus recommendations on imaging in monoclonal plasma cell disorders. The Lancet Oncology. 2019 06;20(6):e302-e312. https://doi.org/10.1016/s14702045(19)30309-2

2. Bray F, Ferlay J, Soerjomataram I, Siegel RL, Torre LA, Jemal A. Global cancer statistics 2018: GLOBOCAN estimates of incidence and mortality worldwide for 36 cancers in 185 countries. CA: A Cancer Journal for Clinicians. 2018 09 12;68(6):394-424. https://doi.org/10.3322/caac.21492

3. Cowan AJ, Allen C, Barac A, Basaleem H, Bensenor I, Curado MP, Foreman K, Gupta R, Harvey J, Hosgood HD, Jakovljevic M, Khader Y, Linn S, Lad D, Mantovani L, Nong VM, Mokdad A, Naghavi M, Postma M, Roshandel G, Shackelford K, Sisay M, Nguyen CT, Tran TT, Xuan BT, Ukwaja KN, Vollset SE, Weiderpass E, Libby EN, Fitzmaurice C. Global Burden of Multiple Myeloma. JAMA Oncology. 201809 01;4(9):1221. https://doi.org/10.1001/ jamaoncol.2018.2128

4. Rajkumar SV, Kumar S. Multiple Myeloma: Diagnosis and Treatment. Mayo Clinic Proceedings. 2016 01;91(1):101119. https://doi.org/10.1016/j.mayocp.2015.11.007

5. Rajkumar SV. Evolving diagnostic criteria for multiple myeloma. Hematology. 2015 Dec 05;2015(1):272-278. https://doi.org/10.1182/asheducation-2015.1.272

6. Hussain A, Almenfi HF, Almehdewi AM, Hamza MS, Bhat MS, Vijayashankar NP. Laboratory Features of Newly Diagnosed Multiple Myeloma Patients. Cureus. 201905 22;. https://doi.org/10.7759/cureus.4716

7. Rajkumar SV, Dimopoulos MA, Palumbo A, Blade J, Merlini G, Mateos M, Kumar S, Hillengass J, Kastritis E, Richardson P, Landgren O, Paiva B, Dispenzieri A, Weiss B, LeLeu X, Zweegman S, Lonial S, Rosinol L, Zamagni E, Jagannath S, Sezer O, Kristinsson SY, Caers J, Usmani SZ, Lahuerta JJ, 
Johnsen HE, Beksac M, Cavo M, Goldschmidt H, Terpos E, Kyle RA, Anderson KC, Durie BGM, Miguel JFS. International Myeloma Working Group updated criteria for the diagnosis of multiple myeloma. The Lancet Oncology. 2014 Nov;15(12):e538-e548. https://doi.org/10.1016/s14702045(14)70442-5

8. Deng S, Zhang B, Zhou Y, Xu X, Li J, Sang S, Zhang W. The Role of 18F-FDG PET/CT in Multiple Myeloma Staging according to IMPeTUs: Comparison of the DurieSalmon Plus and Other Staging Systems. Contrast Media \& Molecular Imaging. 201807 30;2018:1-9. https://doi. org/10.1155/2018/4198673

9. Palumbo A, Avet-Loiseau H, Oliva S, Lokhorst HM, Goldschmidt H, Rosinol L, Richardson P, Caltagirone S, Lahuerta JJ, Facon T, Bringhen S, Gay F, Attal M, Passera R, Spencer A, Offidani M, Kumar S, Musto P, Lonial S, Petrucci MT, Orlowski RZ, Zamagni E, Morgan G, Dimopoulos MA, Durie BG, Anderson KC, Sonneveld P, San Miguel J, Cavo M, Rajkumar SV, Moreau P. Revised International Staging System for Multiple Myeloma: A Report From International Myeloma Working Group. Journal of Clinical Oncology. 201509 10;33(26):2863-2869. https://doi.org/10.1200/ jco.2015.61.2267

10. Hari PN, Zhang M, Roy V, Pérez WS, Bashey A, To LB, Elfenbein G, Freytes CO, Gale RP, Gibson J, Kyle RA, Lazarus HM, McCarthy PL, Milone GA, Pavlovsky S, Reece DE, Schiller G, Vela-Ojeda J, Weisdorf D, Vesole D. Is the international staging system superior to the Durie-Salmon staging system? A comparison in multiple myeloma patients undergoing autologous transplant. Leukemia. 200903 26;23(8):1528-1534. https://doi.org/10.1038/leu.2009.61

[11. Durie BG. The role of anatomic and functional staging in myeloma: Description of Durie/Salmon plus staging system. European Journal of Cancer. 2006 07;42(11):1539-1543. https://doi.org/10.1016/j.ejca.2005.11.037

12. Zamagni E, Tacchetti $P$, Cavo M. Imaging in multiple myeloma: How? When?. Blood. 201902 14;133(7):644651. https://doi.org/10.1182/blood-2018-08-825356

13. Derlin T. Imaging of multiple myeloma: Current concepts. World Journal of Orthopedics. 2014;5(3):272. https://doi. org/10.5312/wjo.v5.i3.272

14. Kosmala A, Bley T, Petritsch B. Imaging of Multiple Myeloma. RöFo - Fortschritte auf dem Gebiet der Röntgenstrahlen und der bildgebenden Verfahren. 201906 11;191(09):805-816. https://doi.org/10.1055/a-0864-2084

15. Shachar B, Prica A, Anconina R, Hawsawy A, MacCrostie P, Langer D, Metser U. Impact of 18F-fluorodeoxyglucose PET/ $\mathrm{CT}$ in the management of patients with plasma cell disorders. Nuclear Medicine Communications. 2020 01;41(1):34-39. https://doi.org/10.1097/mnm.0000000000001113

16. Moreau P, San Miguel J, Sonneveld P, Mateos M, Zamagni E, Avet-Loiseau H, Hajek R, Dimopoulos M, Ludwig H, Einsele H, Zweegman S, Facon T, Cavo M, Terpos E, Goldschmidt H, Attal M, Buske C. Multiple myeloma: ESMO Clinical Practice Guidelines for diagnosis, treatment and follow-up. Annals of Oncology. 2017 07;28:iv52-iv61. https://doi.org/10.1093/annonc/mdx096

17. Caers J, Garderet L, Kortüm KM, O’Dwyer ME, van de Donk NW, Binder M, Dold SM, Gay F, Corre J, Beguin Y, Ludwig H, Larocca A, Driessen C, Dimopoulos MA, Boccadoro M, Gramatzki M, Zweegman S, Einsele H, Cavo M, Goldschmidt H, Sonneveld P, Delforge M, Auner HW, Terpos E, Engelhardt M. European Myeloma Network recommendations on tools for the diagnosis and monitoring of multiple myeloma: what to use and when. Haematologica. 201808 31;103(11):1772-1784. https://doi.org/10.3324/ haematol.2018.189159

18. Messiou C, Kaiser M. Whole-Body Imaging in Multiple Myeloma. Magnetic Resonance Imaging Clinics of North America. 2018 Nov;26(4):509-525. https://doi. org/10.1016/j.mric.2018.06.006

19. van Lammeren-Venema D, Regelink JC, Riphagen II, Zweegman S, Hoekstra OS, Zijlstra JM. 18F-fluorodeoxyglucose positron emission tomography in assessment of myeloma-related bone disease: A systematic review. Cancer. 201109 01;118(8):1971-1981. https://doi. org/10.1002/cncr.26467

20. Moreau P, Attal M, Caillot D, Macro M, Karlin L, Garderet L, Facon T, Benboubker L, Escoffre-Barbe M, Stoppa A, Laribi K, Hulin C, Perrot A, Marit G, Eveillard J, Caillon F, Bodet-Milin C, Pegourie B, Dorvaux V, Chaleteix C, Anderson K, Richardson P, Munshi NC, Avet-Loiseau H, Gaultier A, Nguyen J, Dupas B, Frampas E, KraeberBodere F. Prospective Evaluation of Magnetic Resonance Imaging and [18F]Fluorodeoxyglucose Positron Emission Tomography-Computed Tomography at Diagnosis and Before Maintenance Therapy in Symptomatic Patients With Multiple Myeloma Included in the IFM/DFCI 2009 Trial: Results of the IMAJEM Study. Journal of Clinical Oncology. 201709 01;35(25):2911-2918. https://doi.org/10.1200/ jco.2017.72.2975

21. Sachpekidis C, Goldschmidt H, Dimitrakopoulou-Strauss A. Positron Emission Tomography (PET) Radiopharmaceuticals in Multiple Myeloma. Molecules. 2019 Dec 29;25(1):134. https://doi.org/10.3390/molecules25010134

22. Hillner BE, Siegel BA, Shields AF, Liu D, Gareen IF, Hunt E, Coleman RE. Relationship Between Cancer Type and Impact of PET and PET/CT on Intended Management: Findings of the National Oncologic PET Registry. Journal of Nuclear Medicine. 2008 Nov 07;49(12):1928-1935. https:// doi.org/10.2967/jnumed.108.056713

23. Sachpekidis C, Mai E, Goldschmidt H, Hillengass J, Hose D, Pan L, et al. 18F-FDG Dynamic PET/CT in Patients with Multiple Myeloma Patterns of Tracer Uptake and Correlation With Bone Marrow Plasma Cell Infiltration Rate . Clin Nucl Med. 2015;40:e300-e307.

24. Zamagni E, Cavo M. The role of imaging techniques in the management of multiple myeloma. British Journal of Haematology. 2012 08;:n/a-n/a. https://doi.org/10.1111/ bjh. 12007

25. Bailly C, Leforestier R, Jamet B, Carlier T, Bourgeois M, Guérard F, et al. PET Imaging for Initial Staging and Therapy Assessment in Multiple Myeloma Patients. Int. J. Mol. Sci. 2017;18:445

26. Corso A, Mangiacavalli S. NON-SECRETORY MYELOMA: READY FOR A NEW DEFINITION?. Mediterranean Journal of Hematology and Infectious Diseases. 201708 18;9(1):e2017053. https://doi.org/10.4084/mjhid.2017.053

27. Caers J, Paiva B, Zamagni E, Leleu X, Bladé J, Kristinsson SY, Touzeau C, Abildgaard N, Terpos E, Heusschen R, Ocio E, Delforge M, Sezer O, Beksac M, Ludwig H, Merlini G, Moreau P, Zweegman S, Engelhardt M, Rosiñol L. Diagnosis, treatment, and response assessment in solitary plasmacytoma: updated recommendations from a European Expert Panel. Journal of Hematology \& Oncology. 201801 16;11(1). https://doi.org/10.1186/s13045-017-0549-1

28. Zamagni E, Nanni C, Gay F, Pezzi A, Patriarca F, Bellò M, Rambaldi I, Tacchetti P, Hillengass J, Gamberi B, Pantani L, Magarotto V, Versari A, Offidani M, Zannetti B, Carobolante F, Balma M, Musto P, Rensi M, Mancuso K, Dimitrakopoulou-Strauss A, Chauviè S, Rocchi S, Fard N, Marzocchi G, Storto G, Ghedini P, Palumbo A, Fanti S, 
Cavo M. 18F-FDG PET/CT focal, but not osteolytic, lesions predict the progression of smoldering myeloma to active disease. Leukemia. 2015 Oct 22;30(2):417-422. https://doi. org/10.1038/leu.2015.291

29. Siontis B, Kumar S, Dispenzieri A, Drake MT, Lacy MQ, Buadi F, Dingli D, Kapoor P, Gonsalves W, Gertz MA, Rajkumar SV. Positron emission tomography-computed tomography in the diagnostic evaluation of smoldering multiple myeloma: identification of patients needing therapy. Blood Cancer Journal. 2015 Oct;5(10):e364-e364. https:// doi.org/10.1038/bcj.2015.87

30. Bartel TB, Haessler J, Brown TLY, Shaughnessy JD, van Rhee F, Anaissie E, Alpe T, Angtuaco E, Walker R, Epstein J, Crowley J, Barlogie B. F18-fluorodeoxyglucose positron emission tomography in the context of other imaging techniques and prognostic factors in multiple myeloma. Blood. 200909 03;114(10):2068-2076. https:// doi.org/10.1182/blood-2009-03-213280

31. Zamagni E, Patriarca F, Nanni C, Zannetti B, Englaro E, Pezzi A, Tacchetti P, Buttignol S, Perrone G, Brioli A, Pantani L, Terragna C, Carobolante F, Baccarani M, Fanin R, Fanti S, Cavo M. Prognostic relevance of 18-F FDG $\mathrm{PET} / \mathrm{CT}$ in newly diagnosed multiple myeloma patients treated with up-front autologous transplantation. Blood. 2011 Dec 01;118(23):5989-5995. https://doi.org/10.1182/ blood-2011-06-361386

32. Fonti R, Larobina M, Del Vecchio S, De Luca S, Fabbricini R, Catalano L, Pane F, Salvatore M, Pace L. Metabolic Tumor Volume Assessed by 18F-FDG PET/CT for the Prediction of Outcome in Patients with Multiple Myeloma. Journal of Nuclear Medicine. 2012 Oct 15;53(12):1829-1835. https:// doi.org/10.2967/jnumed.112.106500

33. McDonald JE, Kessler MM, Gardner MW, Buros AF, Ntambi JA, Waheed S, van Rhee F, Zangari M, Heuck CJ, Petty N, Schinke C, Thanendrarajan S, Mitchell A, Hoering A, Barlogie B, Morgan GJ, Davies FE. Assessment of Total Lesion Glycolysis by 18 F FDG PET/CT Significantly Improves Prognostic Value of GEP and ISS in Myeloma. Clinical Cancer Research. 2016 Oct 03;23(8):1981-1987. https://doi.org/10.1158/1078-0432.ccr-16-0235

34. Li Q, Ma J, Li H, Xu W, Cao Z, Liu S, Chen L, Gao S, Yan T, Li D, Wang X, Yue Y, Zhao Z, Wang X, Yang H, Zhao H, Yu Y, Zhang Y, Fan F, Wang Y. Correlation Between Uptake of 18F-FDG During PET/CT and Ki-67 Expression in Patients Newly Diagnosed With Multiple Myeloma Having Extramedullary Involvement. Technology in Cancer Research \& Treatment. 201901 01;18:153303381984906. https://doi.org/10.1177/1533033819849067

35. Cengiz A, Arda HÜ, Döğer F, Yavaşoğlu İ, Yürekli Y, Bolaman AZ. Correlation between baseline 18F-FDG PET/ CT findings and CD38, CD138 expressing myeloma cells in bone marrow and clinical parameters in patiens with multiple myeloma. Turkish Journal of Hematology. 2018 05 28; https://doi.org/10.4274/tjh.2017.0372

36. Li Y, Liu J, Huang B, Chen M, Diao X, Li J. Application of $\mathrm{PET} / \mathrm{CT}$ in treatment response evaluation and recurrence prediction in patients with newly-diagnosed multiple myeloma. Oncotarget. 201608 19;8(15):25637-25649. https://doi.org/10.18632/oncotarget.11418

37. Caldarella C, Treglia G, Isgrò MA, Treglia I, Giordano A. The Role of Fluorine-18-Fluorodeoxyglucose Positron Emission Tomography in Evaluating the Response to Treatment in Patients with Multiple Myeloma. International Journal of Molecular Imaging. 2012;2012:1-6. https://doi. org/10.1155/2012/175803

38. Zamagni E, Nanni C, Mancuso K, Tacchetti P, Pezzi A,
Pantani L, Zannetti B, Rambaldi I, Brioli A, Rocchi S, Terragna C, Martello M, Marzocchi G, Borsi E, Rizzello I, Fanti S, Cavo M. PET/CT Improves the Definition of Complete Response and Allows to Detect Otherwise Unidentifiable Skeletal Progression in Multiple Myeloma. Clinical Cancer Research. 201506 15;21(19):4384-4390. https://doi.org/10.1158/1078-0432.ccr-15-0396

39. Derlin T, Peldschus K, Münster S, Bannas P, Herrmann J, Stübig T, Habermann CR, Adam G, Kröger N, Weber C. Comparative diagnostic performance of 18F-FDG PET/ $\mathrm{CT}$ versus whole-body MRI for determination of remission status in multiple myeloma after stem cell transplantation. European Radiology. 201207 29;23(2):570-578. https://doi. org/10.1007/s00330-012-2600-5

40. Kumar S, Glazebrook KN, Broski SM. Fludeoxyglucose F 18 PET/Computed Tomography Evaluation of Therapeutic Response in Multiple Myeloma. PET Clinics. 2019 07;14(3):391-403. https://doi.org/10.1016/j. cpet.2019.03.006

41. Dimitrakopoulou-Strauss A, Hoffmann M, Bergner R, Uppenkamp M, Haberkorn U, Strauss LG. Prediction of Progression-Free Survival in Patients With Multiple Myeloma Following Anthracycline-Based Chemotherapy Based on Dynamic FDG-PET. Clinical Nuclear Medicine. 2009 09;34(9):576-584. https://doi.org/10.1097/ rlu.0b013e3181b06bc5

42. Lonial S, Anderson KC. Association of response endpoints with survival outcomes in multiple myeloma. Leukemia. 201307 19;28(2):258-268. https://doi.org/10.1038/ leu. 2013.220

43. Landgren O, Devlin S, Boulad M, Mailankody S. Role of MRD status in relation to clinical outcomes in newly diagnosed multiple myeloma patients: a meta-analysis. Bone Marrow Transplantation. 201609 05;51(12):1565-1568. https://doi.org/10.1038/bmt.2016.222

44. Romano A, Palumbo GA, Parrinello NL, Conticello C, Martello M, Terragna C. Minimal Residual Disease Assessment Within the Bone Marrow of Multiple Myeloma: A Review of Caveats, Clinical Significance and Future Perspectives. Frontiers in Oncology. 201908 20;9. https:// doi.org/10.3389/fonc.2019.00699

45. Alonso R, Cedena MT, Gómez-Grande A, Ríos R, Moraleda JM, Cabañas V, Moreno MJ, López-Jiménez J, Martín F, Sanz A, Valeri A, Jiménez A, Sánchez R, Lahuerta JJ, Martínez-López J. Imaging and bone marrow assessments improve minimal residual disease prediction in multiple myeloma. American Journal of Hematology. 201906 09;94(8):853-861. https://doi.org/10.1002/ajh.25507

46. Dammacco F, Rubini G, Ferrari C, Vacca A, Racanelli V. 18F-FDG PET/CT: a review of diagnostic and prognostic features in multiple myeloma and related disorders. Clinical and Experimental Medicine. 201409 14;15(1):1-18. https:// doi.org/10.1007/s10238-014-0308-3

47. Sundaram S, Driscoll J, Fernandez-Ulloa M, Lima M, Malek E. FDG PET imaging in multiple myeloma: implications for response assessments in clinical trials. Am J Nucl Med Mol Imaging. 2018;8(6):421-7.

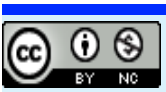

This work is licensed under a Creative Commons AttributionNon Commercial 4.0 International License. 